\title{
Nuclear Factor (NF) KB polymorphism is associated with heart function in patients with heart failure
}

\author{
Diogo GB Santos¹, Marina F Resende1', José G Mill2, Alfredo J Mansur³, José E Krieger and Alexandre C Pereira*1
}

\begin{abstract}
Background: Cardiac remodeling is generally an adverse sign and is associated with heart failure (HF) progression. $\mathrm{NFkB}$, an important transcription factor involved in many cell survival pathways, has been implicated in the remodeling process, but its role in the heart is still controversial. Recently, a promoter polymorphism associated with a lesser activation of the NFKB1 gene was also associated with Dilated Cardiomyopathy. The purpose of this study was to evaluate the association of this polymorphism with clinical and functional characteristics of heart failure patients of different etiologies.
\end{abstract}

Methods: A total of 493 patients with HF and 916 individuals from a cohort of individuals from the general population were investigated. The NFKB1 -94 insertion/deletion ATTG polymorphism was genotyped by High Resolution Melt discrimination. Allele and genotype frequencies were compared between groups. In addition, frequencies or mean values of different phenotypes associated with cardiovascular disease were compared between genotype groups. Finally, patients were prospectively followed-up for death incidence and genotypes for the polymorphism were compared regarding disease onset and mortality incidence in HF patients.

Results: We did not find differences in genotype and allelic frequencies between cases and controls. Interestingly, we found an association between the $\mathrm{ATTG}_{1} / \mathrm{ATTG}_{1}$ genotype with right ventricle diameter $(P=0.001)$, left ventricle diastolic diameter $(P=0.04)$, and ejection fraction ( $E F)\left(P=0.016\right.$ ), being the genotype $A T T G_{1} / A T T G_{1}$ more frequent in patients with $\mathrm{EF}$ lower than $50 \%(P=0.01)$. Finally, we observed a significantly earlier disease onset in ATTG1/ATTG carriers.

Conclusion: There is no genotype or allelic association between the studied polymorphism and the occurrence of HF in the tested population. However, our data suggest that a diminished activation of NFKB1, previously associated with the $A T T G_{1} / A T T G_{1}$ genotype, may act modulating on the onset of disease and, once the individual has $H F$, the genotype may modulate disease severity by increasing cardiac remodeling and function deterioration.

\section{Background}

Cardiac remodeling is defined as alterations in left ventricular (LV) chamber mass, geometry and function, and is associated with heart failure (HF) progression[1]. Remodeling leads to LV dilatation and impaired systolic function and transcends the anatomical changes in ventricular geometry, leading to ultra-structural cellular modifications in cardiomyocytes[2,3]. Nuclear factor $(\mathrm{NF}) \kappa B$ is a central integrator of stress response and cell survival pathways[4]. Its activation is observed in the

* Correspondence: alexandre.pereira@incor.usp.br

${ }^{1}$ Laboratory of Genetics and Molecular Cardiology, Heart Institute (InCor), Sao Paulo University Medical School, Sao Paulo, Brazil

Full list of author information is available at the end of the article myocardial tissue from HF patients of various etiologies[5] suggesting that inflammatory pathways are operant in the development of HF[6].

The Rel/NFkB transcription factor is from a family of evolutionary conserved proteins that are all related through the highly conserved Rel homology binding domain. There are five members of the NFKB family in mammals: p50/p105, p65/RelA, cRel, RelB and p52/ $\mathrm{p} 100$ [7]. In general, transcription activation is dependent on subunit's dimerization. In several tissues, including the heart, the major form of $\mathrm{NFKB}_{\mathrm{B}}$ is the heterodimer p50/p65[8]. The p50 subunit $(50 \mathrm{kDa})$ is encoded in humans by the gene NFKB1 and corresponds to the $\mathrm{N}$ terminus of the cytoplasmic protein p105 (105 kDa)[9]. 
NFkB primarily resides inactive in the cytoplasm by association with $\mathrm{I}_{\kappa} \mathrm{B}$. Its activation can be triggered by a variety of stimuli that ultimately lead to phosphorylation, ubiquitination and degradation of $I \kappa B$, releasing $N F \kappa B$ dimers to nuclear translocation, where $N F \kappa B$ dependent transcription of a large and diverse array of target genes can be initiated and various physiological and pathological processes modulated [10].

NFKB1 transcription activation is associated with the development of several diseases such as asthma, inflammatory arthritis, septic shock, lung fibrosis, cancer, AIDS, inflammatory bowel disease, atherosclerosis, diabetes and stroke[10,11], mainly acting by transcription activation of inflammatory processes[12], but the role of its activation in the heart remains controversial. First, NFKB was believed to act, in general, worsening cardiac remodeling or dysfunction mainly through activation of a proinflammatory pathway enhancing HF[13-17]. However, recently, several studies have found evidence pointing to a new role for NFKB in the HF scenario. In these studies, $\mathrm{NF} \kappa \mathrm{B}$ is thought to play a protective role by acting in an anti-inflammatory pathway, participating in matrix remodeling and attenuating oxidative stress thus mitigating the HF progression [18-21].

Recently, two different in vitro studies observed that an insertion $\left(\mathrm{ATTG}_{2}\right)$ of an ATTG sequence at position -94 of the promoter region of the NFKB1 gene increases transcriptional activity compared to the allele with the deletion $\left(\mathrm{ATTG}_{1}\right)[22,23]$. In humans, the production of the p105 and p50 proteins has been shown to be greater among individuals with the $\mathrm{ATTG}_{2} / \mathrm{ATTG}_{2}$ genotype [23]. The purpose of the present work was to study the association of this functional polymorphism with different phenotypes related to HF through an evaluation of the clinical characteristics of 493 individuals with HF of different etiologies.

\section{Methods}

\section{Study population}

Five-hundred and three (503) patients with heart failure in functional class III or IV of the New York Heart Association were studied. The patients were included as part of a secondary-cohort of HF individuals at a tertiary cardiology care center in Sao Paulo, Brazil (Heart Institute of the Sao Paulo University Medical School). Ascertainment period was from August, 2002 to March, 2004.

The diagnosis of heart failure was made according to previously published criteria $[24,25]$. The classification of the etiologies of heart failure followed previous recommendations[25]. As such, the diagnosis of chronic heart failure was made through both clinical and imaging procedures when necessary. Ischemic cardiomyopathy diagnosis was made when a clear history of previous myocardial infarction and no other probable cause of heart dysfunction was present or, alternatively, through coronary angiography. All patients with the final diagnosis of idiopathic dilated cardiomyopathy were studied through coronary angiography to exclude the possible diagnosis of ischemic cardiomyopathy. In the present analysis we have used data from 493 participants.

\section{Follow-up}

Beginning of follow-up was defined as enrollment in the protocol. Follow-up was assessed in the last outpatient medical visit or by telephone contact. In addition, the mortality database of São Paulo City Authority was also scrutinized to discover patient deaths (ProAim--Programa de Aprimoramento de Informações de Mortalidade do Municipio de São Paulo). Last follow-up was evaluated in April, 2009. Primary end-point studied was overall mortality.

\section{Control population - General population of Vitória/ES, Brazil}

A cross-sectional study of risk factors for cardiovascular diseases was performed in the urban population of Vitoria, Brazil, using the WHO-MONICA project guidelines [26]. The study design was based on cross-sectional research methodology and was developed by means of surveying and analyzing socioeconomic and health data in a probabilistic sample of residents aged 25 to 64 years from the municipality of Vitoria, ES, Brazil. The population was randomized and the sample was socioeconomically, geographically and demographically representative of the residents of this municipality. A selection of 2,268 residential homes located in Vitoria was made and these were visited. The project received approval from the Ethics Committee of the Biomedical Center of Universidade Federal do Espírito Santo (UFES). The selected individuals were asked to attend the Cardiovascular Investigation Clinic of the University Hospital for tests to be performed on the following day. Of the total sample, 1,577 individuals attended. Participants were submitted to physical examination. Major cardiovascular risk factors such as smoking habits, alcohol intake, sedentarism, diabetes and hypertension were inquired. Blood glucose, total cholesterol, lipoprotein fractions, and triglycerides were assayed by standard techniques in a 12-hour fasting blood sample. In the present analysis we have used data from 916 participants.

\section{Left ventricular function assessment}

Left ventricular ejection fraction was determined by $\mathrm{M}$ mode echocardiography. In some patients two-dimensional method was employed, using Simpson. The evaluation of the left ventricular function was performed by the echocardiography staff in a blinded way in relation to the 
genotypes and was conducted according to previously published recommendations[27].

\section{Genotype determination}

Extraction of genomic DNA was performed from leukocytes separated from whole blood using a standard method[28]. DNA samples were further diluted with PCR grade water to a concentration of $10 \mathrm{ng} / \mu \mathrm{L}$. The -94 insertion/deletion polymorphism was detected by a High Resolution Melt technique. The primer sequences were $\mathrm{F}$ 5'-CATGACTCTATCAGCGGCACT-3' and R 5'GGCTCTGGCTTCCTAGCAG-3'. Primers were designed using accession number [GenBank: AF213884.2] including a region that does not possess other polymorphisms than the rs28362491 and to be annealed at $60^{\circ} \mathrm{C}$ using the Primer3 software. The final optimal reaction conditions were empirically determined. The reaction mixture used BioTaq DNA Polymerase (BioQuimica, Brazil) and consisted of $10 \mathrm{ng}$ of genomic DNA, $1 \times$ Assay buffer, $2 \mathrm{mM} \mathrm{MgCl}, 200 \mathrm{nM}$ of each primer, $200 \mu \mathrm{M}$ of dNTPs, 1,5 $\mu \mathrm{M}$ of SYTO9 (Invitrogen, Carlsbad, USA), $0.5 \mathrm{U}$ of BioTaq DNA Polymerase and PCR grade water in a volume of $10 \mu \mathrm{L}$. PCR cycling and HRM analysis was performed on the Rotor-Gene $\mathrm{e}^{\mathrm{mi}} 6000$ equipment (Qiagen, Courtaboeuf, France). The PCR cycling conditions were as follows: one cycle of $94^{\circ} \mathrm{C}$ for $5 \mathrm{~min}$ utes; 35 cycles of $94^{\circ} \mathrm{C}$ for 20 seconds, $60^{\circ}$ for 20 seconds, $72^{\circ} \mathrm{C}$ for 20 seconds; and one cycle of $72^{\circ} \mathrm{C}$ for 5 minutes and an HRM step from 72 to $94^{\circ} \mathrm{C}$ rising at $0.1^{\circ} \mathrm{C}$ per second. Curve genotypes were confirmed by an electrophoresis run on a 4\% agarose gel (UltraPure ${ }^{\mathrm{th}}$ - Agarose 1000, Invitrogen, Carlsbad, USA) stained with ethidium bromide $(1 \mu \mathrm{g} / \mathrm{ml})$. Ten percent of the samples were randomly chosen and re-genotyped and agreement was of $100 \%$.

\section{Statistical analysis}

Data are presented as means \pm standard deviation (SD) for continuous variables and as frequencies for categorical variables. Differences in baseline characteristics among groups were analyzed using ANOVA for continuous variables and the Chi-square test for categorical variables. Hardy-Weinberg equilibrium was evaluated by a Chi-square test.

The probability of survival and disease onset was evaluated by the Kaplan Meier method relative to clinical variables and relative to genotypes of studied polymorphism. Comparisons were made with the log-rank test. Death (overall) was the primary end-point.

Statistical analyses were performed with the SPSS software 13.0. A $p$ value $<0.05$ was considered significant.

\section{Ethics}

The investigation conforms to the principles outlined in the Declaration of Helsinki and the study protocol was approved by the Ethics Committee for Medical Research on Human Beings of the Hospital das Clínicas from University of São Paulo Medical School. Signed informed consent was obtained from all participants from both samples.

\section{Results}

\section{Genotyping the rs28362491 polymorphism}

Genotype status was obtained for 493 and 916 individuals of the HF and Control samples, respectively. All genotype frequencies were consistent with those predicted by the Hardy-Weinberg equilibrium. Table 1 shows allelic and genotype frequencies among patients and controls where ATTG ${ }_{1}$ and $\mathrm{ATTG}_{2}$ represent the allele with the deletion and insertion, respectively. Neither the allelic, nor the genotype frequencies revealed any difference between patients and controls.

\section{Clinical and demographic evaluation}

We tested both patient and control samples for association with clinical and demographic characteristics (Tables 2 and 3, respectively). The only significant association was observed between diabetes and the ATTG1 allele in the HF population.

Table 1: Allelic and genotype frequencies of NFKB1 -94 insertion/deletion among pacients and control.

\begin{tabular}{|c|c|c|c|}
\hline & $\begin{array}{l}\text { Patients } \\
\mathrm{N}=493\end{array}$ & $\begin{array}{l}\text { Controls } \\
\mathrm{N}=916\end{array}$ & p value \\
\hline \multicolumn{4}{|c|}{ Genotype Frequencies } \\
\hline $\mathrm{A} T T \mathrm{G}_{2} \mathrm{~A} T \mathrm{TG}_{2}$ & 0.345 & 0.345 & \\
\hline$A T T G_{2} A T T G_{1}$ & 0.507 & 0.509 & 0.99 \\
\hline $\mathrm{ATTG} \mathrm{ATTG}_{1}$ & 0.148 & 0.146 & \\
\hline \multicolumn{4}{|l|}{ Allelic Frequencies } \\
\hline $\mathrm{ATTG} \mathrm{G}_{2}$ & 0.59 & 0.575 & 0.93 \\
\hline $\mathrm{ATTG}_{1}$ & 0.41 & 0.425 & \\
\hline
\end{tabular}


Table 2: Demographic and clinical characteristics of the HF population according to -94 insertion/deletion genotype.

\begin{tabular}{|c|c|c|c|c|}
\hline & ATTG2/ATTG2 & ATTG1/ATTG2 & ATTG1/ATTG1 & p value \\
\hline Patients & 170 & 250 & 73 & - \\
\hline Age, years & $59 \pm 15.2$ & $58.2 \pm 14$ & $54.7 \pm 13.7$ & 0.09 \\
\hline \multicolumn{5}{|l|}{ Gender } \\
\hline Male n (\%) & $95(56)$ & $137(62)$ & $53(59)$ & 0.45 \\
\hline \multicolumn{5}{|l|}{ Ethnicity n (\%) } \\
\hline Blacks & $12(23.5)$ & $29(57.0)$ & $10(19.5)$ & \\
\hline Mulattos & $26(38.8)$ & $26(38.8)$ & $15(22.4)$ & 0.08 \\
\hline Whites & $129(35.5)$ & $185(51.0)$ & $48(13.5)$ & \\
\hline \multicolumn{5}{|l|}{ Biochemical } \\
\hline Serum sodium (mmol/L) & $59.61 \pm 1.9$ & $59.45 \pm 2.0$ & $59.48 \pm 1.7$ & 0.72 \\
\hline Hemoglobin (g/dL) & $13.03 \pm 2.3$ & $13 \pm 2.1$ & $13.48 \pm 2$ & 0.19 \\
\hline Total Cholesterol (mg/dL) & $194.95 \pm 50.4$ & $185.53 \pm 50.9$ & $195.85 \pm 56.6$ & 0.17 \\
\hline Triglycerides (mg/dL) & $123.55 \pm 67.2$ & $124.5 \pm 66.4$ & $119.15 \pm 7$ & 0.87 \\
\hline $\mathrm{HDL}(\mathrm{mg} / \mathrm{dL})$ & $47.22 \pm 14.7$ & $43.77 \pm 15.8$ & $45.61 \pm 17.1$ & 0.13 \\
\hline LDL (mg/dL) & $122.74 \pm 42.9$ & $117 \pm 39.5$ & $123.7 \pm 48.5$ & 0.41 \\
\hline Creatinin (mg/dL) & $1.36 \pm 0.72$ & $1.35 \pm 0.75$ & $1.33 \pm 0.78$ & 0.95 \\
\hline \multicolumn{5}{|l|}{ Diabetes n (\%) } \\
\hline Yes & $33(35.5)$ & $54(54)$ & $6(6.5)$ & 0.035 \\
\hline No & $125(34.4)$ & $177(49)$ & $61(16.6)$ & \\
\hline BMI $\left(\mathrm{kg} / \mathrm{m}^{2}\right)$ & $25.36 \pm 5.9$ & $26.1 \pm 5.2$ & $24.2 \pm 4.93$ & 0.07 \\
\hline Heart Rate (pm) & $79.3 \pm 13.8$ & $79.5 \pm 12.2$ & $80.2 \pm 14.6$ & 0.9 \\
\hline Diastolic Blood Pressure (mmHg) & $73.9 \pm 16.4$ & $76.4 \pm 18.4$ & $78.5 \pm 20.9$ & 0.19 \\
\hline Systolic Blood Pressure (mmHg) & $120.4 \pm 30$ & $121.5 \pm 30.6$ & $125.6 \pm 31.5$ & 0.58 \\
\hline
\end{tabular}

\section{Functional Evaluation}

Patients possessing the $\mathrm{ATTG}_{1} / \mathrm{ATTG}_{1}$ genotype presented higher right and left ventricular diameters demonstrated by higher right ventricle (RV) diameter $(P=$ $0.001)$, left ventricle $(\mathrm{LV})$ diastolic diameter $(P=0.04)$ and a tendency towards higher mean LV systolic diameter $(P$ $=0.06)$. RV and LV remodeling was accompanied by functional deterioration, as can be observed by the lower ejection fraction (EF) in patients with the $\mathrm{ATTG}_{1} / \mathrm{ATTG}_{1}$ genotype $(\mathrm{P}=0.016)$. Cardiac remodeling and functional deterioration were not observed in the control population (Table 4). However, it is interesting to note a non-significant tendency of lower mean EF in carriers of the $\mathrm{ATTG}_{1} / \mathrm{ATTG}_{1}$ genotype in control individuals $(\mathrm{p}=$ $0.10)$.

We further analyzed differences in genotype frequencies between patients selected based on an EF above or below 50\%. Frequencies in patients with $\mathrm{EF}>50 \%$ were: $40 \% \quad \mathrm{ATTG}_{2} / \mathrm{ATTG}_{2}, \quad 52 \% \quad \mathrm{ATTG}_{1} / \mathrm{ATTG}_{2}$ and $8 \%$ $\mathrm{ATTG}_{1} / \mathrm{ATTG}_{1}$, while in patients with EF $<50 \%$ they were: $32 \% \mathrm{ATTG}_{2} / \mathrm{ATTG}_{2}, 49 \% \mathrm{ATTG}_{1} / \mathrm{ATTG}_{2}$ and $19 \%$
$\mathrm{ATTG}_{1} / \mathrm{ATTG}_{1}$. Genotype ATTG $1 / \mathrm{ATTG}_{1}$ was more frequent in patients with $\mathrm{EF}$ lower than $50 \%(P=0.01)$.

Finally, we observed that individuals who carry the $\mathrm{ATTG}_{1} / \mathrm{ATTG}_{1}$ genotype presented an earlier disease onset. Figure 1 panel A shows the Kaplan-Meier curves for disease onset in individuals harboring the different $N F K B 1$ genotypes. Interesting, those who have the $\mathrm{ATTG}_{1} / \mathrm{ATTG}_{1}$ genotype presented the disease, on average, 7 years sooner than those with the $\mathrm{ATTG}_{2} / \mathrm{ATTG}_{2}$ genotype. No significant difference was observed in Kaplan-Meier curve for mortality (Figure 1, panel B).

\section{Discussion}

The role of $\mathrm{NF}_{K} \mathrm{~B}$ in heart failure has been studied by several authors[6] and it still remains controversial. Many studies applied different methods to model the role of NFkB in the heart failure scenario. These ranged from coronary artery ligation to mouse and rat models that block the NFKB1 gene [13-17,19]. Beyond its interaction with other subunits, NFKB can act in the cell by two other forms, the p105 and the homodimer (p50) 2 . The p105 
Table 3: Demographic and clinical characteristics of the Control population according to -94 insertion/deletion genotype.

\begin{tabular}{|c|c|c|c|c|}
\hline & ATTG2/ATTG2 & ATTG1/ATTG2 & ATTG1/ATTG1 & p value \\
\hline Number & 316 & 466 & 134 & - \\
\hline Age, years & $44.36 \pm 10.46$ & $45.01 \pm 10.6$ & $43.95 \pm 10.54$ & 0.5 \\
\hline \multicolumn{5}{|l|}{ Gender } \\
\hline Male n (\%) & $136(43)$ & $171(36.7)$ & $58(43.3)$ & 0.14 \\
\hline \multicolumn{5}{|l|}{ Ethnicity n (\%) } \\
\hline Blacks & $18(31)$ & $28(48.3)$ & $12(20.7)$ & \\
\hline Mulattos & $150(33.1)$ & $237(52.3)$ & $66(14.6)$ & 0.35 \\
\hline Whites & $122(38.6)$ & $151(47.8)$ & $43(13.6)$ & \\
\hline \multicolumn{5}{|l|}{ Biochemical } \\
\hline Hemoglobin (mg/dL) & $13.83 \pm 1.47$ & $13.61 \pm 1.41$ & $13.74 \pm 1.51$ & 0.12 \\
\hline Total Cholesterol (mg/dL) & $215.43 \pm 40.73$ & $218.52 \pm 43.87$ & $214.16 \pm 49.9$ & 0.47 \\
\hline Triglycerides (mg/dL) & $124.07 \pm 82.3$ & $130.6 \pm 92.12$ & $139.24 \pm 91.21$ & 0.23 \\
\hline $\mathrm{HDL}(\mathrm{mg} / \mathrm{dL})$ & $45.46 \pm 11.91$ & $46.46 \pm 12.06$ & $44.73 \pm 11.42$ & 0.25 \\
\hline $\mathrm{LDL}(\mathrm{mg} / \mathrm{dL})$ & $145.59 \pm 37.76$ & $146.77 \pm 39.29$ & $142.32 \pm 44.17$ & 0.52 \\
\hline Creatinin (mg/dL) & $0.97 \pm 0.20$ & $0.96 \pm 0.02$ & $0.98 \pm 0.17$ & 0.84 \\
\hline \multicolumn{5}{|l|}{ Diabetes n (\%) } \\
\hline Yes & $22(29)$ & $45(58)$ & $10(13)$ & 0.37 \\
\hline No & $294(35)$ & $420(50)$ & $123(15)$ & \\
\hline BMI $\left(\mathrm{kg} / \mathrm{m}^{2}\right)$ & $26.34 \pm 5.08$ & $26.55 \pm 5.08$ & $26.47 \pm 4.9$ & 0.84 \\
\hline Heart Rate (pm) & $70.40 \pm 12.13$ & $70.81 \pm 10.46$ & $70.73 \pm 8.94$ & 0.95 \\
\hline Diastolic Blood Pressure $(\mathrm{mmHg})$ & $83.27 \pm 13.06$ & $82.57 \pm 13.45$ & $81.73 \pm 12.26$ & 0.51 \\
\hline Systolic Blood Pressure (mmHg) & $126 \pm 20.22$ & $128.6 \pm 22.29$ & $127.77 \pm 22.45$ & 0.25 \\
\hline
\end{tabular}

forms complexes with non-NFkB family proteins providing a crosstalk between NFKB and other signaling pathways that regulate different cellular functions[29]. The $(\mathrm{p} 50)_{2}$, first considered a repressor of transcription, is now believed to also act as a transcription activator. Ultimately, the processing of p105 is in part dependent on the setting of NFkB dimmers in the surroundings, differing in each kind of cell[30]. The complex transcriptional and post-translational modification of the NFKB1 gene and product, respectively, might be the reason why the several studies addressing ablation of the NFKB1 gene present different conclusions: sometimes observing that $\mathrm{NFKB}$ (p50) acts worsening HF by activation of a pro-inflammatory pathway[13-16] whereas in other, protecting the heart by activation of anti-inflammatory pathways, matrix remodeling or attenuation of oxidative stress[19].

In the present study, we evaluated the role of a polymorphism that was previously described to be associated with diminished transcription of NFKB1 due to a four base pair deletion in the promoter region of the gene and resulting in the loss of binding of nuclear proteins, thus, leading to a reduced promoter activity.
The rs28362491 polymorphism was first described by Karban et al[22] and associated to an increased risk for ulcerative colitis. This polymorphism has been associated with diverse human diseases but, only recently, Zhou et al. described an association with heart disease[31]. They observed, in 177 patients with dilated cardiomyopathy (DCM), a higher prevalence of the genotypes $\mathrm{ATTG}_{2} /$ $\mathrm{ATTG}_{2}+\mathrm{ATTG}_{1} / \mathrm{ATTG}_{2}$ in DCM patients, indicating that $\mathrm{ATTG}_{2}$ carriers have increased risk of DCM. However, they only observed a non-statistical higher $\mathrm{ATTG}_{2}$ allelic frequency in DCM patients (62.7 vs. 57.1). Herein, we used diverse HF etiologies, including DCM, and did not observe neither genotype nor allelic distribution differences between patients and controls $(P=0.99$ and $P=$ 0.96 , respectively). This lack of association was also observed when we compared only patients with the DCM etiology $(\mathrm{n}=50)$ with controls $(P=0.13$ genotype frequencies, $P=0.37$ allelic frequencies, data not shown), and, despite the low statistical power due to the small number of patients with this specific diagnosis, we observed that the $\mathrm{ATTG}_{2}$ allelic frequency in DCM patients is lower than in control individuals (50\% vs. 
Table 4: Functional data for the HF and Control population according to -94 insertion/deletion genotype.

\begin{tabular}{|c|c|c|c|c|c|c|c|c|}
\hline & \multicolumn{4}{|c|}{ Patients } & \multicolumn{4}{|c|}{ Controls } \\
\hline & ATTG2/ATTG2 & ATTG1/ATTG2 & ATTG1/ATTG1 & p value & ATTG2/ATTG2 & ATTG1/ATTG2 & ATTG1/ATTG1 & $p$ value \\
\hline $\mathrm{LAD}, \mathrm{mm}$ & $46 \pm 9.2$ & $46.7 \pm 8.8$ & $48.9 \pm 8.7$ & 0.09 & $33.31 \pm 3.1$ & $33 \pm 2.86$ & $33.83 \pm 3.42$ & 0.3 \\
\hline $\mathrm{AD}, \mathrm{mm}$ & $32.8 \pm 6.4$ & $32.6 \pm 5.2$ & $32.3 \pm 6.9$ & 0.88 & $32 \pm 2.9$ & $31.32 \pm 2.86$ & $31.58 \pm 2.74$ & 0.18 \\
\hline $\mathrm{RVD}, \mathrm{mm}$ & $25 \pm 7.73$ & $27.07 \pm 8.10$ & $31.07 \pm 7.83$ & 0.001 & $16.55 \pm 4.33$ & $17.29 \pm 4.77$ & $17.27 \pm 4$ & 0.43 \\
\hline \multicolumn{9}{|l|}{ Left Ventricle } \\
\hline $\mathrm{IS}, \mathrm{mm}$ & $9.8 \pm 2.5$ & $9.7 \pm 2.2$ & $9.70 \pm 2.1$ & 0.81 & $8.98 \pm 1.27$ & $8.93 \pm 1.15$ & $8.91 \pm 1.10$ & 0.9 \\
\hline PWT, mm & $9.6 \pm 2.1$ & $9.5 \pm 1.9$ & $9.5 \pm 2$ & 0.95 & $8.92 \pm 1.22$ & $8.75 \pm 1.08$ & $8.77 \pm 1$ & 0.38 \\
\hline $\mathrm{DD}, \mathrm{mm}$ & $60.8 \pm 11.5$ & $61.6 \pm 11.4$ & $65 \pm 11.3$ & 0.04 & $48.09 \pm 4.84$ & $48.58 \pm 4.8$ & $48.76 \pm 5$ & 0.6 \\
\hline $\mathrm{SD}, \mathrm{mm}$ & $48 . \pm 13.7$ & $49.3 \pm 14.3$ & $53.5 \pm 15.1$ & 0.06 & $28.7 \pm 3.74$ & $29.26 \pm 4.10$ & $29.74 \pm 4.82$ & 0.24 \\
\hline$E F,(\%)$ & $47.9 \pm 18.5$ & $45.6 \pm 19$ & $39.5 \pm 18.2$ & 0.016 & $71.63 \pm 4.77$ & $71 \pm 5.2$ & $69.70 \pm 6.85$ & 0.1 \\
\hline Mass, g & $247 \pm 104$ & $249 \pm 89$ & $267 \pm 88$ & 0.36 & $151 \pm 47.87$ & $151 \pm 42.7$ & $152 \pm 46.9$ & 0.99 \\
\hline
\end{tabular}

LAD - Left Atrium Diameter, AD - Aortic Diameter, RVD - Right Ventricle Diameter, IS - Intraventricular Septum, PWT - Posterior Wall Thickness, DD - Diastolic Diameter, SD - Systolic Diameter, EF - Ejection Fraction

57.5\%), indicating an opposite direction for the putative association. These data suggest that the presence of the $\mathrm{ATTG}_{2}$ allele itself does not represent a risk factor for DCM or HF in general in our population.

Even considering the problems of the NFKB1 ablation models, they are useful to point towards interesting aspects of NFkB physiology in the heart. Recently, Timmers et al[19] reported enhanced cardiac remodeling and dysfunction in NFKB p50 knockout mice after myocardial infarction. Knockout mice presented reduced ejection fraction and higher LV diastolic and systolic volume, indicating cardiac remodeling and deteriorated function. In our analyses we observed a significant difference in EF,
LV diastolic and RV diameter only in HF patients $(P=$ $0.016, P=0.04$ and $P=0.001$, respectively). Signs of impaired heart function were all associated with the $\mathrm{ATTG}_{1} / \mathrm{ATTG}_{1}$ genotype. Additionally, we observed a tendency in LV systolic diameter, LA diameter and mass to be higher in the $\mathrm{ATTG}_{1} / \mathrm{ATTG}_{1}$ genotype. These data corroborate Timmers', and is also supported by another recent study where a model with attenuated activation of $\mathrm{NF} \kappa \mathrm{B}$ presented similar cardiac modifications [18]. Curiously, although a low EF is known to be the strongest predictor of mortality in HF, we did not observe an association of the $\mathrm{ATTG}_{1}$ allele with survival in this
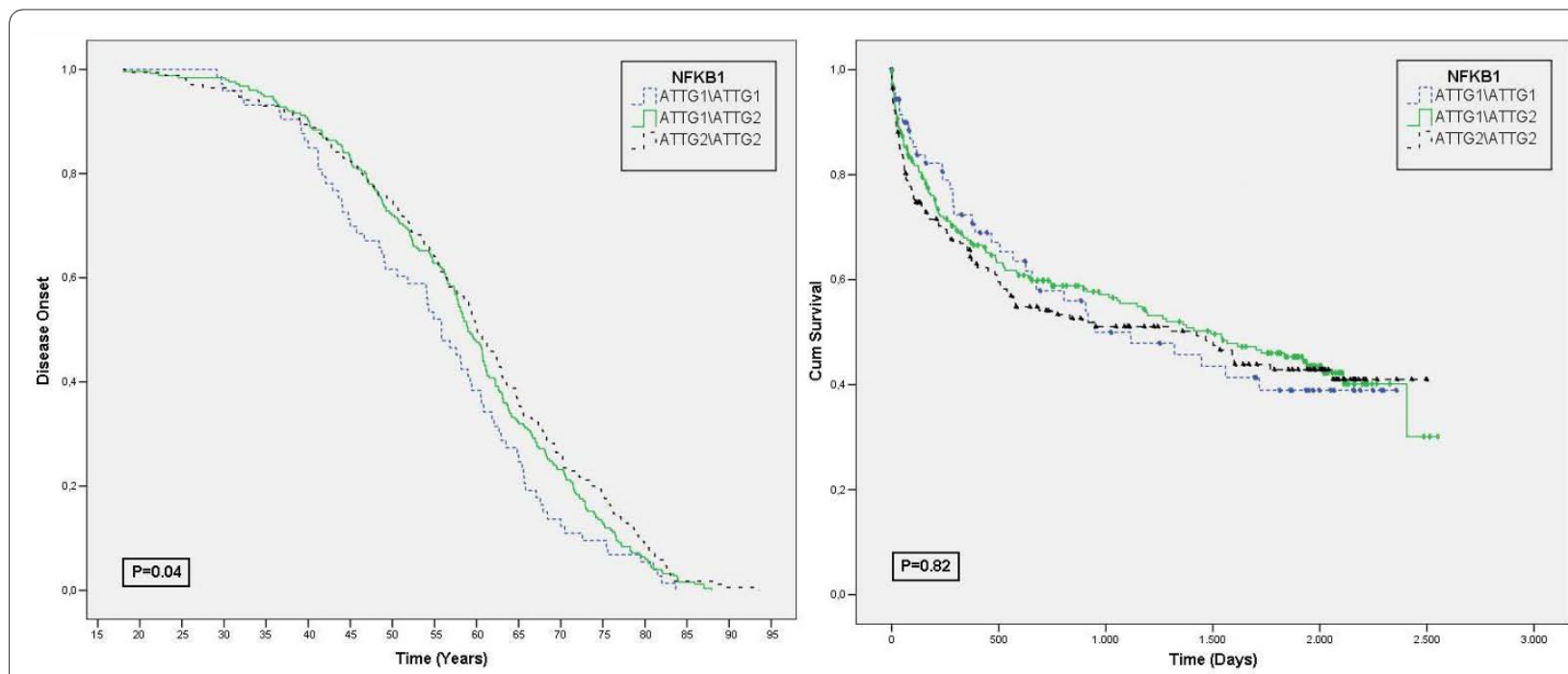

Figure 1 A Kaplan-Meier curve for Disease Onset (A) and Mortality (B). Blue line represents genotype ATTG /ATGG $_{1}$, Green line genotype ATTG $/$ $A T T G_{2}$ and black line genotype $A T T G_{2} / A T T G_{2}$. In $B$, the different forms represent the event death for each genotype. 
patient cohort $(\mathrm{P}=0.8$ ) (Figure 1, panel B). Interestingly, the same was observed in $\mathrm{p} 50 \mathrm{KO}$ mice and in mice with attenuated expression of the NFKB1 gene[18,20]. Nevertheless, we demonstrated that carriers of the $\mathrm{ATTG}_{1} /$ ATTG $_{1}$ genotype exhibit a significant anticipated disease onset (of nearly 7 years). Taken together, these data suggest that the presence of $\mathrm{ATTG}_{1} / \mathrm{ATTG}_{1}$ genotype is involved with an enhanced cardiac remodeling process and impaired heart function. The implications of this association to long term prognosis remain to be explored.

The main limitation herein is the lack of replication of the significant associations in another equivalent, independent cohort. This, beyond the confirmation of data, would also give other important information regarding survival and may shed light into why we were not able to observe the expected higher mortality in patients with the $\mathrm{ATTG}_{1} / \mathrm{ATTG}_{1}$ genotype.

\section{Conclusion}

There is no genotype or allelic association between the studied polymorphism and the development of HF. However, our data suggest that a diminished activation of $N F K B 1$, previously associated with the $\mathrm{ATTG}_{1} / \mathrm{ATTG}_{1}$ genotype, may act modulating the onset of disease and, once the individual has HF, the genotype may modulate disease severity by increasing cardiac remodeling and function deterioration.

\section{Competing interests}

The authors declare that they have no competing interests.

\section{Authors' contributions}

DGBS carried out the molecular genetic studies, statistical analysis and drafted the manuscript. ACP participated in the design of the study, statistical analysis and coordinated experiments and manuscript preparation. JEK participated in the design of the study. JGM and AJM were responsible for patient selection and characterization. All authors read and approved the final manuscript.

\section{Acknowledgements}

This work was supported by Fundação de Amparo à Pesquisa do Estado de São Paulo [Grant numbers 2008/51652-0, 2009/0952421-4].

\section{Author Details}

'Laboratory of Genetics and Molecular Cardiology, Heart Institute (InCor), Sao Paulo University Medical School, Sao Paulo, Brazil, ${ }^{2}$ Department of Physiology, Federal University of Espírito Santo, Vitória, Brazil and ${ }^{3}$ Cardiology Department, Clinical Division, Heart Institute (Incor), Sao Paulo University Medical School, Sao Paulo, Brazil

Received: 19 January 2010 Accepted: 9 June 2010

Published: 9 June 2010

\section{References}

1. Cohn JN, Ferrari R, Sharpe N: Cardiac remodeling--concepts and clinical implications: a consensus paper from an international forum on cardiac remodeling. Behalf of an International Forum on Cardiac Remodeling. J Am Coll Cardiol 2000, 35:569-582.

2. St John Sutton M, Pfeffer MA, Plappert T, Rouleau JL, Moye LA, Dagenais GR, Lamas GA, Klein M, Sussex B, Goldman S, et al: Quantitative twodimensional echocardiographic measurements are major predictors of adverse cardiovascular events after acute myocardial infarction. The protective effects of captopril. Circulation 1994, 89:68-75.
3. Bolognese L, Neskovic AN, Parodi G, Cerisano G, Buonamici P, Santoro GM, Antoniucci D: Left ventricular remodeling after primary coronary angioplasty: patterns of left ventricular dilation and long-term prognostic implications. Circulation 2002, 106:2351-2357.

4. Pahl HL: Activators and target genes of Rel/NF-kappaB transcription factors. Oncogene 1999, 18:6853-6866.

5. Wong SC, Fukuchi M, Melnyk P, Rodger I, Giaid A: Induction of cyclooxygenase- 2 and activation of nuclear factor-kappaB in myocardium of patients with congestive heart failure. Circulation 1998, 98:100-103

6. Valen G, Yan ZQ, Hansson GK: Nuclear factor kappa-B and the heart. J Am Coll Cardiol 2001, 38:307-314

7. Gilmore TD: The Rel/NF-kappaB signal transduction pathway: introduction. Oncogene 1999, 18:6842-6844

8. Norman DA, Yacoub MH, Barton PJ: Nuclear factor NF-kappa B in myocardium: developmental expression of subunits and activation by interleukin-1 beta in cardiac myocytes in vitro. Cardiovasc Res 1998, 39:434-441.

9. Heron E, Deloukas P, van Loon AP: The complete exon-intron structure of the 156-kb human gene NFKB1, which encodes the p105 and p50 proteins of transcription factors NF-kappa B and I kappa B-gamma: implications for NF-kappa B-mediated signal transduction. Genomics 1995, 30:493-505

10. Baldwin AS Jr: Series introduction: the transcription factor NF-kappaB and human disease. J Clin Invest 2001, 107:3-6.

11. Chen F, Castranova V, Shi X, Demers LM: New insights into the role of nuclear factor-kappaB, a ubiquitous transcription factor in the initiation of diseases. Clin Chem 1999, 45:7-17.

12. Tak PP, Firestein GS: NF-kappaB: a key role in inflammatory diseases. $J$ Clin Invest 2001, 107:7-11.

13. Frantz S, Tillmanns J, Kuhlencordt PJ, Schmidt I, Adamek A, Dienesch C, Thum T, Gerondakis S, Ertl G, Bauersachs J: Tissue-specific effects of the nuclear factor kappaB subunit p50 on myocardial ischemiareperfusion injury. Am J Pathol 2007, 171:507-512

14. Frantz S, Hu K, Bayer B, Gerondakis S, Strotmann J, Adamek A, Ertl G, Bauersachs J: Absence of NF-kappaB subunit p50 improves heart failure after myocardial infarction. FASEB J 2006, 20:1918-1920.

15. Kawano S, Kubota T, Monden Y, Tsutsumi T, Inoue T, Kawamura N, Tsutsui $H$, Sunagawa K: Blockade of NF-kappaB improves cardiac function and survival after myocardial infarction. Am J Physiol Heart Circ Physiol 2006 291:H1337-1344.

16. Kawamura N, Kubota T, Kawano S, Monden Y, Feldman AM, Tsutsui $H$ Takeshita A, Sunagawa K: Blockade of NF-kappaB improves cardiac function and survival without affecting inflammation in TNF-alphainduced cardiomyopathy. Cardiovasc Res 2005, 66:520-529.

17. Brown M, McGuinness M, Wright T, Ren X, Wang Y, Boivin GP, Hahn H, Feldman AM, Jones WK: Cardiac-specific blockade of NF-kappaB in cardiac pathophysiology: differences between acute and chronic stimuli in vivo. Am J Physiol Heart Circ Physiol 2005, 289:H466-476.

18. Hikoso S, Yamaguchi O, Nakano Y, Takeda T, Omiya S, Mizote I, Taneike M, Oka T, Tamai T, Oyabu J, et al.: The I\{kappa\}B kinase $\{$ beta\}/nuclear factor $\{k a p p a\} B$ signaling pathway protects the heart from hemodynamic stress mediated by the regulation of manganese superoxide dismutase expression. Circ Res 2009, 105:70-79.

19. Timmers L, van Keulen JK, Hoefer IE, Meijs MF, van Middelaar B, den Ouden K, van Echteld CJ, Pasterkamp G, de Kleijn DP: Targeted deletion of nuclear factor kappaB p50 enhances cardiac remodeling and dysfunction following myocardial infarction. Circ Res 2009, 104:699-706.

20. Timmers L, Sluijter JP, van Keulen JK, Hoefer IE, Nederhoff MG, Gouman MJ, Doevendans PA, van Echteld CJ, Joles JA, Quax PH, et al:: Toll-like receptor 4 mediates maladaptive left ventricular remodeling and impairs cardiac function after myocardial infarction. Circ Res 2008 102:257-264.

21. Misra A, Haudek SB, Knuefermann P, Vallejo JG, Chen ZJ, Michael LH, Sivasubramanian N, Olson EN, Entman ML, Mann DL: Nuclear factorkappaB protects the adult cardiac myocyte against ischemia-induced apoptosis in a murine model of acute myocardial infarction. Circulation 2003, 108:3075-3078.

22. Karban AS, Okazaki T, Panhuysen Cl, Gallegos T, Potter JJ, Bailey-Wilson JE, Silverberg MS, Duerr RH, Cho JH, Gregersen PK, et al.: Functional 
annotation of a novel NFKB1 promoter polymorphism that increases risk for ulcerative colitis. Hum Mol Genet 2004, 13:35-45.

23. Park JY, Farrance IK, Fenty NM, Hagberg JM, Roth SM, Mosser DM, Wang MQ, Jo H, Okazaki T, Brant SR, Brown MD: NFKB1 promoter variation implicates shear-induced NOS3 gene expression and endothelial function in prehypertensives and stage I hypertensives. Am J Physiol Heart Circ Physiol 2007, 293:H2320-2327.

24. McKee PA, Castelli WP, McNamara PM, Kannel WB: The natural history of congestive heart failure: the Framingham study. N Engl J Med 1971, 285:1441-1446.

25. Hunt SA: ACC/AHA 2005 guideline update for the diagnosis and management of chronic heart failure in the adult: a report of the American College of Cardiology/American Heart Association Task Force on Practice Guidelines (Writing Committee to Update the 2001 Guidelines for the Evaluation and Management of Heart Failure). J Am Coll Cardiol 2005, 46:e1-82.

26. Pereira AC, Sposito AC, Mota GF, Cunha RS, Herkenhoff FL, Mill JG, Krieger $J E$ : Endothelial nitric oxide synthase gene variant modulates the relationship between serum cholesterol levels and blood pressure in the general population: new evidence for a direct effect of lipids in arterial blood pressure. Atherosclerosis 2006, 184:193-200.

27. Sahn DJ, DeMaria A, Kisslo J, Weyman A: Recommendations regarding quantitation in M-mode echocardiography: results of a survey of echocardiographic measurements. Circulation 1978, 58:1072-1083.

28. Miller SA, Dykes DD, Polesky HF: A simple salting out procedure for extracting DNA from human nucleated cells. Nucleic Acids Res 1988 16:1215.

29. Pereira SG, Oakley F: Nuclear factor-kappaB1: regulation and function. Int J Biochem Cell Biol 2008, 40:1425-1430.

30. Hayden MS, Ghosh S: Signaling to NF-kappaB. Genes Dev 2004 18:2195-2224

31. Zhou B, Rao L, Peng Y, Wang Y, Li Y, Gao L, Chen Y, Xue H, Song Y, Liao M, Zhang L: Functional polymorphism of the NFKB1 gene promoter is related to the risk of dilated cardiomyopathy. BMC Med Genet 2009, 10:47.

Pre-publication history

The pre-publication history for this paper can be accessed here: http://www.biomedcentral.com/1471-2350/11/89/prepub

doi: $10.1186 / 1471-2350-11-89$

Cite this article as: Santos et al., Nuclear Factor (NF) ?B polymorphism is associated with heart function in patients with heart failure BMC Medical Genetics 2010, 11:89

Submit your next manuscript to BioMed Centra and take full advantage of:

- Convenient online submission

- Thorough peer review

- No space constraints or color figure charges

- Immediate publication on acceptance

- Inclusion in PubMed, CAS, Scopus and Google Scholar

- Research which is freely available for redistribution

Submit your manuscript at www.biomedcentral.com/submit
C Biomed Central 